\title{
LITERATURA POLICIAL Y LITERATURA MUNDIAL
}

\author{
Hernán Maltz \\ Universidad de Buenos Aires, Consejo Nacional de Investigaciones Científicas y Técnicas, \\ Instituto de Filología y Literaturas Hispánicas "Dr. Amado Alonso" \\ Buenos Aires, Argentina \\ hermaltz@gmail.com
}

\section{RESUMEN / ABSTRACT}

Elaboramos una aproximación entre el género policial y algunos debates recientes en torno a la problemática de la literatura mundial. Luego de mencionar la incorporación de lo global como tema de algunas ficciones, de explicitar el lugar de enunciación del analista y de repasar brevemente los aportes que piensan dicha intersección, planteamos dos abordajes: por un lado, nos apoyamos en los trabajos de Casanova y Moretti para pensar la literatura policial desde una perspectiva global y asimétrica; por otro, a partir de Luhmann, elaboramos otra aproximación teórica desde una perspectiva sistémica.

Palabras Clave: literatura policial, literatura mundial, literaturas comparadas, sistemas, Luhmann.

\section{CRIME FICTION AND WORLD LITERATURE}

The article proposes an approach to crime fiction and recent debates around the problem of world literature. After determining the incorporation of the global as a theme in some fictions, evincing the place of enunciation of the analyst, and briefly reviewing the contributions that explore that intersection, two approaches are offered. On the one hand, and following the works by Casanova and Moretti, crime fiction is considered from a global and asymmetric perspective. On the other, and inspired by Luhmann, another theoretical approach is elaborated from a systemic perspective.

KEYWORDS: Crime Fiction, World Literature, Comparative Literature, Systems, Luhmann.

Recepción: 16/03/2018

Aprobación: 02/06/2018 


\section{LA TRAMA DE LA GLOBALIZACIÓN}

En este ensayo pensamos un cruce conceptual entre el género policial y algunos debates recientes en torno a la problemática de la literatura mundial. Para ello, la novela El enigma de París (2007), de Pablo De Santis, nos resulta muy útil como punto de partida desde un lugar de enunciación -de un scholar-argentino.

Recordemos, muy brevemente, que el argumento de esta novela se centra en una reunión de una organización internacional de investigadores, los Doce Detectives, con el propósito de dar a conocer sus saberes y métodos, en el marco de la Exposición Universal de París en 1889 -año en que se inaugura la torre Eiffel-. El protagonista de la historia, Sigmundo Salvatrio -el único asistente que sobrevive a la academia de formación del detective argentino Renato Craig en Buenos Aires-, viaja a París para presenciar dicha reunión, debido a la imposibilidad de hacerlo por parte de su mentor. Sin embargo, ya en Francia, las teorías de detección expuestas en el simposio de detectives pronto pasan a un lugar secundario, cuando una serie de muertes los obliga a poner en práctica sus saberes.

Aquí, no obstante, no nos interesa volver sobre los detalles de la trama, pero sí nos seduce la idea de una novela argentina que intenta captar la condición transnacional del género policial, a través de un elenco de personajes que se remite a un mapa no exhaustivo pero bastante amplio de naciones, ya que los Doce Detectives cuentan con representantes de Alemania, Argentina, España, Estados Unidos, Francia, Grecia, Holanda, Inglaterra, Italia, Japón, Polonia y Portugal, además de que algunos de sus ayudantes representan a naciones colonizadas, tal como sucede en los casos del detective inglés Lawson y su asistente hindú Dandavi o del detective portugués Zagala y su ayudante Benito, "un negro brasileño de agilidad prodigiosa" (De Santis 2008 [2007]: 24).

En un trabajo en que analiza lo que denomina "the plot of globalization", Beecroft interpreta ciertas ficciones en soporte escrito, como 2666 (2004) de Roberto Bolaño, y audiovisual, como Babel (2006) de Alejandro González Iñárritu, a la luz de las operaciones narrativas con las que tematizan e incorporan en sus propias diégesis un argumento en torno a "lo global". Dicho crítico apunta que la técnica narrativa no es en absoluto novedosa, pues sostiene que un siglo antes de su artículo ya se discutía el concepto de entrelacement respecto a algunas novelas medievales francesas (2016: 200). Pero, según él, lo nuevo de estas ficciones de comienzos del siglo XXI "is the use of this device as way to project onto the level of form the paranoiac 
interconnectedness of life in a globalized era, and the expansion of the scale on which these narratives are interwoven to the level of the planet itself" (2016: 200). Si intentamos aplicar esta caracterización a El enigma de París, quizá debiera ser desdoblada del siguiente modo: por un lado, el contexto de producción de la novela, a comienzos del siglo XXI, puede efectivamente ponerla a la par de las obras de Bolaño y González Iñárritu, aunque, por otro, el desarrollo de los eventos fictivos, en la transición entre los siglos XIX y XX, en todo caso anticipa o muestra un momento previo a dicha idea "paranoica" en torno a "lo global", más propia del siglo XXI, tal como afirma Beecroft.

Es cierto que, a diferencia de las obras de Bolaño y González Iñárritu, la estructura de la novela de De Santis no se construye a partir del entrecruzamiento de historias, sino que la operación narrativa es más básica y consiste en juntar detectives de distintas nacionalidades en un lugar que ha sido descripto como el centro del mundo artístico hacia fines del siglo XIX y principios del XX -si seguimos no solo a Casanova (2001 [1999]), sino también, por ejemplo, las ideas que se sostienen sobre los pintores y poetas en el documental París: The Luminous Years (2010) de Perry Miller Adato-. Pero, de cualquier modo, El enigma de París plantea una narración a través de un diálogo internacional, tal como sucede en el coloquio en que los distintos detectives exponen sus concepciones acerca de cómo concebir el enigma -en el segundo capítulo, titulado justamente "El simposio"-. En este sentido, la novela sí apela a una internacionalización de su trama que la acerca a 2666 y la aleja, según la comparación de Beecroft, de Cien años de soledad (1967) de García Márquez, obra que se sustenta en una construcción metafórica que relaciona a una familia con la categoría del Estado-nación: "Where One Hundred Years of Solitude [...] explicitly thematizes the nation-state, evenas its reception is governed by its Latin American 'regional' status, 2666 (like the rest of Bolaño's work) eschews the paradigm of the nation-state altogether, to tell a story which cannot be contained within national borders" (2016: 202).

Por lo tanto, El enigma de París, particularmente con su imagen de los detectives de distintas nacionalidades reunidos y debatiendo sobre cómo cada uno entiende y define el enigma, puede ser interpretada no solo como un balance retrospectivo y panorámico de la literatura policial, sino también empleada como un punto de partida para concebir, desde Argentina, una perspectiva mundial sobre el género policial. 


\section{LO POLICIAL, LO MUNDIAL Y LO INTER-NACIONAL DESDE UN LUGAR DE ENUNCIACIÓN ARGENTINO}

No es ninguna novedad que el lugar de enunciación ocupa un lugar importante a la hora de hablar de literatura mundial, especialmente a raíz de los giros epistemológicos que visibilizan posiciones eurocéntricas -en el caso de la literatura comparada tradicional-, relaciones de poder en la definición de identidades y alteridades, etcétera. Así, si bien a veces esto se da por sentado, consideramos que un primer paso metodológico para plantear un cruce entre género policial y literatura mundial es la explicitación del lugar desde el que se enuncia, pues aun cuando la literatura mundial pueda ser entendida como una construcción mental hipotética (Damrosch 2003: 111), en todo caso lo es a través de un enunciador concreto $y$, tal como venimos anunciando, nuestra reflexión debe partir de considerar nuestra posición de argentinidad. Tal como advierte Bermann, no podemos perder de vista "how inevitably partial is our view of the 'world' -and how that view changes radically depending upon where we stand. If we are in China, Tanzania, Peru, Syria, or India, our perspective on and access to world literature will differ dramatically from that in England or North America" (2012: 176), especialmente cuando, aun en la posibilidad de gestar un concepto "democrático" de literatura mundial, no deja de tratarse de un juego desnivelado y que conlleva relaciones de poder (Bermann 2012: 175). En efecto, ya Arac (2002) ha puesto en evidencia la supremacía de la lengua inglesa en los estudios sobre literatura mundial, hecho que tiene un correlato específico en la preeminencia anglo-americana de críticos dedicados al género policial en lengua inglesa (King 2014: 8-9) ${ }^{1}$. En este sentido, insistimos, El enigma de París se convierte en una ficción muy significativa, dado que nos permite ingresar en los debates de la ficción policial como literatura mundial desde una posición concreta en el planeta (y esto no debe ser soslayado incluso cuando, como veremos, formulemos una aproximación a la literatura mundial que pueda y busque prescindir de los anclajes en torno a categorías de lo nacional) $)^{2}$.

\footnotetext{
Es decir, la preeminencia del inglés es doble: en el corpus de literatura policial canónica y en los trabajos críticos sobre ella.

2 Desde luego, no es la única novela que puede llevarnos por este itinerario. Tanto Crímenes imperceptibles (2003) de Guillermo Martínez como El camino de Ida (2013) de Ricardo Piglia nos presentan a un protagonista argentino en suelo extranjero -británico en un caso, norteamericano en el otro-, aunque, de todos modos, estas serían novelas en las
} 
Una vez efectuada la aclaración sobre el lugar concreto de nuestra enunciación, deberíamos recordar que la presencia de lo mundial en la literatura policial tampoco es novedosa. En algunos clásicos del género observamos motivos y argumentos internacionales; pensemos, por ejemplo, en la variedad de sospechosos de distintas nacionalidades que se presentan en "Los crímenes de la calle Morgue" de Poe o en las tramas de novelas como Estudio en escarlata de Conan Doyle o La piedra lunar de Wilkie Collins, que llevan algunas de sus acciones cruciales hacia tierras alejadas de Inglaterra-Estados Unidos e India, respectivamente-. Las ficciones tradicionales del género nos habilitan a hablar, entonces, no tanto de una caracterización global -en el sentido de las interconexiones paranoicas planteadas por Beecroft (2016: 200)-, sino más bien de un panorama internacional; y, para ser más precisos, incluso podríamos usar un guión: inter-nacional, es decir, con énfasis en construcciones de motivos y tramas "entre naciones" (característica a la que también suscribe El enigma de Paris) $)^{3}$.

Así como el policial canónico incluye una tematización sobre lo internacional, la gestación de esta literatura en la Argentina se nutre de modelos genéricos de otros países, ya desde su propio comienzo, cuando Raúl Waleis (Luis V. Varela), en su carta al editor que precede a La huella del crimen (2009 [1877]), se declara heredero de Edgar Allan Poe y Émile Gaboriau (Waleis 2009: 23-24). A lo largo de su historia, si bien es una tendencia la ambición de gestar un policial nacional, siempre se toman explícitamente paradigmas extranjeros: Borges construye su modelo de policial en base a Poe y Chesterton, en tanto que Piglia se remite a Hammett y Chandler. En este sentido, aquella repetida cita de Stuart Hall sobre el "afuera constitutivo" (2003: 18) de la identidad a través de la otredad se vuelve pertinente una vez más, desde el momento en que el policial argentino debe ser pensado, desde sus comienzos, bajo el influjo de modelos genéricos de otros países, tal como ha expuesto Setton (2012) en su libro sobre los orígenes del policial argentino vinculados con la recepción de modelos genéricos ingleses, franceses y alemanes.

que hay una bilateralidad nacional más que una multiplicidad (y, para ser justos, deberíamos decir que, aún en su multiplicidad, El enigma de París también posee una bilateralidad, que no debemos obviar, entre Francia y la Argentina, los dos países entre los que se desarrollan los hechos fictivos).

Asimismo, y más allá de las marcas en las propias ficciones, tampoco debemos olvidar la temprana internacionalización del género en sus dimensiones de producción, circulación y traducción, ya desde comienzos del siglo XVIII (Pepper y Schmid 2016: 1). 


\section{LITERATURAS COMPARADAS, LITERATURA MUNDIAL Y GÉNERO POLICIAL}

Por lo tanto, en buena medida la historia de la literatura policial argentina es una historia propia de los estudios de literatura comparada. En el marco de los debates en torno a esta disciplina y sus vaivenes teóricos e institucionales -como las provocaciones sobre su obsolescencia (Spivak 2003) o los cierres de departamentos de literaturas comparadas en distintas universidades norteamericanas (Ferris 2011; Domínguez, Saussy y Villanueva 2016)-, consideramos pertinente su consideración, por ejemplo, a través de los argumentos de Domínguez, Saussy y Villanueva (2016), quienes esgrimen la propia publicación y existencia de su libro como un síntoma de la pervivencia de la disciplina. Más allá de que las definiciones clásicas sobre la literatura comparada -como las de Texte o Van Tieghem- no puedan sobrevivir sin cambios, de todas formas algo de su espíritu indisciplinado (Ferris 2011) sigue siendo de utilidad para la reflexión.

Asimismo, de particular interés nos resulta el empleo del sintagma "literatura mundial", por parte de Moretti (2000a), como un problema -comenzando por la propia denominación de la disciplina-, sumado al hecho de que, en los últimos años, esta subdisciplina o disciplina ha cobrado mayor importancia en sus relaciones con la comparatística (Bermann 2012) ${ }^{4}$. En efecto, D'haen ofrece un breve compendio, en vínculo con la publicación de artículos y libros, como indicador del resurgimiento de la literatura mundial desde mediados y fines de la década de 1990 y, en lo sustantivo, a partir del siglo XXI:

The return of interest in the subject was heralded in 1994 by the collective volume Reading World Literature: Theory, History, Practice, edited by Sarah Lawall. In 1999 there followed Pascale Casanova's République mondiale des lettres. Franco Moretti in 2000 published "Conjectures on World Literature" in the New Left Review. This article immediately drew heavy critical fire, and became the focus of much vigorous debate springing up in English on world literature. The various reactions to his article by Christopher Prendergast, Jonathan Arac,

\footnotetext{
Para una aproximación a los vínculos entre literatura comparada y literatura mundial, nos remitimos a los trabajos de Huggan (2011) y Bermann (2012), quienes coinciden en señalar que se trata de sintagmas distintos, con trayectorias diferentes, aunque muchas veces convergentes y/o complementarias.
} 
Emily Apter, and others provoked Moretti to "More Conjectures on World Literature," published in the New Left Review again in 2003. Prendergast in 2004 collected a number of articles, some of them, like his own leading off the volume, reactions to Casanova and Moretti, in Debating World Literature. Moretti continued the debate with Graphs, Maps, Trees: Abstract Models for Literary Study (2005), and "Evolution, World Systems, Weltliteratur" (2006). In the meantime had appeared David Damrosch's 2003 What is World Literature? which quickly became the reference for most further discussions of the subject (D'haen 2012: 1-2).

A estas referencias, D'haen suma otras menciones, entre ellas: Comparative Literature in an Age of Globalization, editado en 2006 por Haun Saussy y basado en el reporte de 2004 para la Asociación Norteamericana de Literatura Comparada, The Idea of World Literature (2006) de John Pizer, The Translation Zone: A New Comparative Literature (2006) de Emily Apter, Mapping World Literature (2008) de Mads Rosendahl Thomsen y How to Read World Literature (2009) de David Damrosch (D’haen 2012: 2). Sin ninguna ambición de ser exhaustivos, podríamos añadir la aparición de algunos volúmenes colectivos que cuentan con aportes de distintos especialistas y que intentan sintetizar y alimentar distintas discusiones teóricas, históricas y conceptuales: A Companion to Comparative Literature (2011), editado por Behdad y Thomas, The Routledge Companion to World Literature (2012), editado por D'haen, Damrosch y Kadir, o Companion to Comparative Literature, World Literatures, and Comparative Cultural Studies (2013), editado por Tötösy de Zepetneky Mukherjee -y una buena síntesis de la historia de la disciplina podemos hallarla en el libro de D'haen que venimos citando: The Routledge Concise History of World Literature (2012)-.

En el marco de esta creciente producción de trabajos sobre literatura mundial, algunos se han orientado a reflexionar sobre el vínculo entre literatura mundial -o literaturas comparadas, según el caso-y el concepto de genre. En esta dirección, hallamos, por ejemplo, los desarrollos de Heath (2004), Garrido Miñambres (2010), Siskind (2012) y Gupta (2016), que, con distintos énfasis, varían en sus abordajes: Siskind sostiene que el concepto de género ha sido olvidado durante muchos años y es preciso retomarlo, mientras que Garrido Miñambres considera que el mismo siempre ha ocupado un lugar central; Siskind opta por una mirada de orden programático en su intervención y afirma que hace falta pensar un nuevo sistema de géneros, mientras que Gupta nos recuerda que el actual paradigma con sus nomenclaturas -"Gothic 
novels, sensation novels, romances, detective fiction, fantasies, science fiction, adventure stories, and so on" (2016: 217-218)- en verdad es un fenómeno bastante nuevo, no anterior a las décadas de 1960 y 1970; Heath coloca un mayor énfasis en el concepto de genre y luego lo proyecta a nivel mundial, mientras que Siskind reflexiona sobre el carácter inicialmente mundial del género - tal como ejemplifica con el caso del realismo mágico-. Más allá de sus diferencias, todos ellos tratan de pensar el cruce entre los conceptos de genre y literatura mundial, menos para dar una respuesta definitiva que para reproblematizar cada uno de los términos de la intersección -además de la propia intersección ${ }^{5}$.

Específicamente en relación con nuestro objetivo, en 2017 se publica una compilación de artículos bajo el título de Crime Fiction as World Literature, editado por Nilsson, Damrosch y D'haen, en cuyo prólogo, escrito a seis manos por ellos tres, sintetizan algunas premisas relevantes, tales como: la significativa participación del género policial en la literatura mundial -en cuyo panorama es uno de los géneros más diseminados-; la existencia de una multimillonaria industria multimedia que genera una circulación de libros, traducciones, películas y programas televisivos a escala mundial; el lugar que

Y, por supuesto, las elaboraciones en torno a estos conceptos arrastran otros, como el vínculo entre literatura mundial y literaturas masivas y populares -al respecto, podemos remitirnos al aporte de Baetens (2012), que sostiene que, más que la oposición entre estos términos, es necesario remitirse al cambiante significado de "literatura"-. Del mismo modo, no perdemos de vista que lo mismo sucede con el propio concepto de genre: si bien el presente artículo lo omite de manera voluntaria (pues supone otra discusión que sencillamente no entra en este texto), al menos deberíamos tener presente que se trata igualmente de un término problemático y que posee, a modo de síntesis, dos grandes líneas en las que ha sido elaborado, tal como resume Habjan:

genre theory offered two radical notions of literary genre. At one extreme, genres were understood as classes forming a system that can be either logically prescribed, as in neoclassical taxonomic conceptions of genre, or historically described, as in, for example, Tzvetan Todorov's proposition "to call genres only the classes of texts that have been historically perceived as such" [...]. At the other extreme, genres were seen as symbolic resolutions of social contradictions: "the idea is that literary genres are problem-solving devices, which address a contradiction of their environment, offering an imaginary resolution by means of their formal organization," writes Franco Moretti in a recent defense of this view [...]. (2016: 2-3).

Desde luego, las citas de Todorov y Moretti podrían reemplazarse por otros teóricos que han sostenido tesis similares anteriormente, como Bajtín (2011 [1982]) para las ideas de Todorov o Bazin (2005 [1971]) para las de Moretti. 
ocupa el género policial en términos de su faceta masiva y popular -frente a ciertos desarrollos teóricos del pasado que circunscribían la literatura mundial a un reducido corpus de obras consagradas $-{ }^{6}$; la doble valencia del policial, en tanto herencia literaria pero también en su entrelazamiento con el crecimiento de la sociedad de consumo y con los procesos históricos de industrialización; el vínculo del policial con los cambios del propio modo de producción capitalista globalizado, con el ejemplo puntual, en el mercado del libro, del pasaje de casas editoras nacionales a conglomerados internacionales de multimedios; la propia práctica de escritura de los autores que siguen de cerca las producciones de sus pares de otros países -sin que haya un estricto modelo de "centro" y "periferia"-; y, en una de las cuestiones que más nos interesa, el planteo de que los estudios sobre el género policial, hasta el día de hoy, se han enmarcado fundamentalmente en trabajos sobre literaturas nacionales o regionales o en el área de la cultura popular (Nilsson, Damrosch y D'haen 2017: 1-9). En efecto, si volvemos al caso argentino, comprobamos una marcada tendencia a una delimitación nacional o regional en los títulos de los estudios sobre literatura policial publicados en los últimos años: Diagonales del género. Estudios sobre el policial argentino (2013 [2001]) de Néstor Ponce, La ley y el crimen. Usos del relato policial en la narrativa argentina (1880-2000) (2008) de Sonia Mattalia, Cadáveres en el armario. El policial palimpséstico en la literatura argentina contemporánea (2011) de Osvaldo di Paolo, Nuevos secretos. Transformaciones del relato policial en América Latina. 1990-2000 (2012) de Ezequiel de Rosso y Los orígenes de la narrativa policial en la Argentina: recepción y transformación de modelos genéricos alemanes, franceses e ingleses (2012) de Román Setton. Incluso en el caso de los trabajos de Setton y De Rosso que, aún sin hacer mención a la disciplina, poseen una raíz comparatística significativa, en general estos trabajos no se plantean el problema de la literatura policial como literatura mundial.

Si bien Crime Fiction as World Literature es la publicación más reciente en esta área, no debemos soslayar que no es la primera antología de ensayos que piensa en el policial a escala mundial. En la introducción a dicho libro, los autores mencionan tres antecedentes: Investigating Identities: Questions

\footnotetext{
Aunque los autores aclaran, en este sentido, otro aspecto interesante del género policial: su doble inscripción tanto en la literatura masiva como, en algunos casos, en la denominada “alta literatura" (Nilsson, Damrosch y D’haen 2017: 4).
} 
of Identity in Contemporary International Crime Fiction (2009), editado por Krajenbrink y Quinn, Cross-Cultural Connections in Crime Fictions (2012), editado por Vivien Miller y Helen Oakley, y The Foreign in International Crime Fiction: Transcultural Representations (2012), editado por Anderson, Miranda y Pezzotti, a los que debemos agregar el volumen editado por Pepper y Schmid, Globalization and the State in Contemporary Crime Fiction: A World of Crime (2016).En estos cinco libros (incluimos el de Nilsson, Damrosch y D'haen), si bien hay algunos textos que piensan específicamente "lo global" de lo policial y lo policial en "lo global"-como los aportes de Erdmann (2009) y su idea de un mapa de la literatura policial mundial o Schmid (2012) y el análisis del espacio como factor significativo de la literatura policial-, en general los abordajes tienden a ser de autores y obras particulares. Aun cuando incluyen análisis con, por ejemplo, la tematización sobre la criminalidad global del capitalismo, las interpretaciones de los trabajos de estos volúmenes suelen basarse en un concepto o una categoría que se rastrea en la obra de un único autor. En este sentido, percibimos en estas antologías algo así como una sugerencia implícita derivada de cierto efecto de agregación: hablar de la sumatoria de algunos autores y de algunas obras de distintas partes del planeta significa, a fin de cuentas, hablar del mundo. Pero, en general, estos ensayos evitan pensar el mundo y su infinidad o, en todo caso, optan por nombrarlo con sinécdoques, con fragmentos o con conceptos ordenadores -como el Estado, en el volumen de Pepper y Schmid, o la identidad, en el de Krajenbrink y Quinn-, por lo que, a fin de cuentas, "lo mundial" se convierte menos en un eje de reflexión que en un recipiente que abarca ensayos que se remitan a distintas partes del mundo.

El planteo de que los estudios sobre el género policial, hasta el día de hoy, se han enmarcado fundamentalmente en trabajos sobre literaturas nacionales o regionales es afirmado no solo por Nilsson, Damrosch y D'haen, sino también por Stewart King. Este crítico, de hecho, posee un significativo artículo, publicado en 2014 y titulado de igual manera que el libro de aquellos tres autores, en que expone algunas ideas para un abordaje de la literatura policial como literatura mundial (King 2014). Entre ellas, King plantea que una condición mundial del género policial debe medirse no solo a través de números de ventas y de traducciones a escala global, sino también por medio de referencias intertextuales (2014: 11) -afirmación sensata pero que, en todo caso, nos devuelve al linaje más tradicional de los estudios comparados. Sin embargo, el análisis textual no es suficiente $\mathrm{y}$, a partir de los planteos del propio King, en otras palabras deberíamos decir que la condición del policial 
como literatura mundial acarrea una perspectiva tanto dentro como fuera de los textos. Quizás inspirado en Moretti y su afirmación respecto a que leer más siempre es deseable pero no puede ser la solución (2000a: 55), King consigna que, a pesar de las dificultades, "a world-literature approach to crime fiction can be achieved, but not by reading more novels" (2014: 13). Entre sus propuestas, el crítico postula algunas líneas de abordaje de la literatura policial mundial que, según él, podrían ser: un seguimiento del desarrollo mundial de un subgénero en particular, como la hard-boiled novel o el spy thriller -aunque, claro está, aun tratándose de subgéneros, esto parece una empresa muy extensa- o de algún tipo de dispositivo específico, como el clásico motivo del denominado "locked-room mystery" - dispositivo que, huelga decir, ya ha sido analizado por Cook (2011) en algunas obras canónicas-; un acercamiento a un evento o fenómeno histórico a través del prisma del género policial, particularmente a través de los ejes de la legalidad y la justicia -King piensa los ejemplos de cómo el género representa el nazismo a través de exponentes de diferentes países o de cómo algunas novelas se encargan de hacer lo propio con etapas posdictatoriales de algunos países como Argentina o Estonia-; el análisis de representaciones de mujeres, de homosexuales, de etnias o de clases igualmente puede ser un buen prisma para observar aspectos del orden social a través del policial; y también el crítico considera el estudio de una obra en particular, con énfasis en su circulación y recepción a escala internacional (King 2014: 15-16). Desde luego, estas propuestas son muy razonables aunque, asimismo, debemos reconocer que varias de ellas ya han sido parcialmente efectuadas, aunque se trate de estudios que no piensen particularmente en el vínculo entre literatura policial y literatura mundial. Otra propuesta de King, quizás una de las más sustantivas de su texto, consiste en que el policial como literatura mundial debe ser abordado como lo hacen muchos lectores del género, sin discriminar por países: "Many readers of crime fiction read the genre in a worldly way, and to develop crime fiction as world literature, scholars need to create an analytical practice that reflects this" (2014: 14) ${ }^{7}$. Pasemos, entonces, a esbozar una primera vuelta de consideraciones para un enfoque mundial sobre el género policial.

Si bien es cierto que el recorte de objetos de estudio que parten de una delimitación nacional es un vicio derivado de cierta exigencia institucional de la academia, King sostiene que este tipo de abordajes siguen siendo necesarios en el marco de una perspectiva mundial y desnacionalizada sobre el género (lo que, por supuesto suscribimos). 


\section{TODO Y TOTALIDAD, UNIDAD Y DESIGUALDAD}

Hay una definición de Prendergast, siempre útil, desde la negación; él consigna que, para comenzar, la literatura mundial no es toda la literatura -no puede ser así. Es imposible pensar en la delimitación de algo que tiende a ser infinito: "'World' here [...] does not mean 'global' (in the sense of all the literatures of the world) but rather 'international' structures that arise and transactions that occur across national borders" (2004: 6). Pues bien, algo parecido podríamos decir sobre la literatura policial a escala mundial: tampoco puede ser toda la literatura policial producida en el mundo, dado que es un segmento infinito de ese universo infinito que es toda la literatura. Pero, como ya dijimos, los libros citados que recopilan trabajos sobre obras y escritores específicos parecerían rehuir esta observación: "the majority of the chapters are limited to the national tradition to which the author or text belongs, be it Catalan or Canadian, Algerian or Argentine. The responsibility for making the international connections between texts and authors is largely left to the editors of the respective collections and, of course, to those readers who read more than one chapter" (King 2014: 12). El problema, entonces, consiste en que al no abordar en concreto la distinción entre un todo infinito y una totalidad cognoscible -bajo ciertos parámetros teóricos, pero concebible y cognoscible a fin de cuentas-, se pierde de vista y se hace más difusa la posibilidad de esta última.

Sin embargo, más allá del problema de la infinidad de lo policial dentro del problema de la infinidad de la literatura mundial, parecería que la literatura policial mundial sí tiene algunas pautas de ordenación (o, al menos, posee a primera vista cierto orden que la literatura "a secas" parece no tener). En principio, deberíamos recordar que existe un canon de autores más limitado. Más allá de posibles, necesarias e inevitables discusiones, hay una suerte de podio de nombres que incluye, de parte de la vertiente clásica, a Edgar Allan Poe, Arthur Conan Doyle y Agatha Christie y, del lado del policial negro, a Samuel Dashiell Hammett y Raymond Chandler -desde luego, se trata de una lista con un absoluto dominio de la lengua inglesa y que, en todo caso, debería ser balanceada, al menos, con algunas presencias en lengua francesa, como Emile Gaboriau o Gaston Leroux-. Podemos pensar en trabajos críticos producidos en distintas partes del mundo y que justamente efectúan un análisis del género a partir de esta suerte de canon de la narrativa policial -canon que varía de un crítico a otro, por supuesto, aunque los nombres principales suelen mantenerse-, como los de los norteamericanos Knight 
(1980) y Priestman (1990), el español Valle (2006) o incluso los ensayos de escritores como Škvorecký (1967) o Piglia (1979; 2005; 2006 [1986]). Desde luego, no queremos decir que el estudio de la literatura policial como literatura mundial consista meramente en una selección de un puñado de obras canónicas -tal como King (2014) postula que no hay que hacer-, aunque, así como Alexander (1990) plantea que la lectura de los clásicos en el campo de la sociología sienta una base común de entendimiento entre los profesionales de la disciplina, algo similar podríamos sostener sobre un núcleo de ficciones que cualquier persona que pretende discutir en el área del género policial debería conocer razonablemente ${ }^{8}$.

El caso argentino nos sirve para mostrar una forma en que se piensa la literatura policial, en la que un sistema nacional es descripto, al menos parcialmente, como una resultante de las producciones de otros sistemas nacionales -inglés, norteamericano, francés, etcétera-, tal como plantean la mayoría de los estudios, ya desde el fundacional Asesinos de papel de Lafforgue y Rivera (1996 [1977]). Dicho abordaje lo encontramos, en efecto, en distintos libros sobre la historia general de la literatura policial, que encuentran y resuelven que la forma más sencilla de concebir y presentar la información es, en lo sustantivo, según las producciones de las naciones $-\mathrm{y}$ los autores- tal como sucede en los casos de Biografia de la novela policiaca (1956) de Mira, Historia de la novela policiaca (1967) de Hoveyda, Breve historia de la novela policiaca (1962) de Del Monte o La novela policíaca (1973) de Díaz. Sin embargo, pensar la literatura policial mundial como sumatoria de literaturas policiales nacionales acarrea, desde luego, cierto peligro de tomar la suma de las partes por la totalidad.

8 Adherimos a Knight cuando afirma que, más allá de los autores canónicos y las formas más estandarizadas de practicar el policial, "there is a broader and more varied generation of the genre" (2012: 7). Pero, asimismo, no debemos perder de vista que uno de los sentidos en los que la literatura policial se constituye como literatura mundial es justamente a través de la configuración de un canon de ficciones policiales - un canon, al decir de Moretti, como un conjunto de muy pocos libros que ocupan un espacio muy extenso (2000b: 211)-. La configuración de un canon también supone la participación de rivales que han quedado en el olvido, tal como ocurre con los ejemplos de los escritores contemporáneos a Conan Doyle con los que trabaja Moretti (2000b) y que forman parte del proceso del "matadero" de la literatura, es decir, de su alta selectividad y su eliminación de la mayoría de las obras en visiones posteriores y retrospectivas sobre la historia de la literatura -en esta línea, además del citado trabajo de Moretti, resulta esclarecedor el sintagma "the great unread", acuñado por Cohen (2009), para pensar en esa inmensidad infinita de la literatura. 
Stephen Heath señala que uno de los rasgos de la literatura mundial consiste en su capacidad para moverse entre literaturas y culturas (2004: 166) -concepción que, por supuesto, es similar al planteo de Damrosch (2003) cuando define la literatura mundial por su capacidad para traspasar su cultura de origen-. Así, podemos derivar en cierta idea de una posible literatura policial mundial como una totalidad coherente y unificada. Sin embargo, si nos detenemos en este tipo de afirmación, posiblemente nos quedaríamos con cierta mirada que no contemple las asimetrías ni las relaciones de poder. En este punto, se vuelve pertinente y necesario retomar los aportes de Moretti (2000a) y Casanova (2001 [1999]), quienes, como sostiene D'haen (2012), galvanizan, rejuvenecen y reorientan el debate sobre literatura mundial. Ambos, apoyados teóricamente en Wallerstein y Braudel, conciben la literatura mundial como una y desigual -es decir, a la noción de unidad se le añade la de lo desigual, lo asimétrico, lo, en última instancia, regido por relaciones de poder-. Pues bien, en el caso de la literatura policial, podríamos sostener una concepción similar, en la que hay algunos productores dominantes y otros dominados; valgan como ejemplos los países de Latinoamérica, en los que el género policial es una adaptación, reconversión o modificación activa por parte de autores locales, pero siempre con una apoyatura en modelos extranjeros. Recordemos, por cierto, las afirmaciones de Ayala Gauna y su queja respecto a una suerte de complejo de inferioridad de algunos de sus escritores compatriotas, que "sostienen la imposibilidad del florecimiento de un género policial con ambiente y tipos netamente argentinos. Para ellos el detective solo puede moverse a gusto en las proximidades de Scotland Yard, de la Sureté o del F.B.I., teniendo como campo de acción principal a Londres, París, Nueva York o Chicago" (Ayala Gauna 1979 [1955]: 43). Además, esta cita nos puede servir para, igualmente, señalar la existencia de algunos centros urbanos que son capitales literarias de manera doble, en la realidad y en la literatura (Casanova 2001 [1999]), y para pensar en una ordenación desigual del mundo literario a la que el género policial no escapa.

Otro foco de problematización -ligado a la perspectiva relacional de una red de poderes asimétricos- viene dado por el aparentemente incuestionado carácter occidental de la literatura policial. Aunque no faltan críticos que busquen opciones sobre los orígenes del policial en otras geografías -como las historias del Juez Di en China (Nilsson, Damrosch y D'haen 2017: 2)-, en principio deberíamos acordar que el modelo de policial que conocemos es prevalentemente europeo y norteamericano -más allá de sus adaptaciones y reconversiones en otras geografías-. Esto no quita, desde luego, que 
debamos hacer entrar en el horizonte a los estudios poscoloniales -o, quizá mejor, decoloniales (Mignolo 2007) - y poner justamente en cuestión su estatuto europeo -el mismo problema que acarrea la comparatística-. Pero, en todo caso, creeríamos que el problema aquí no pasa por luchar contra "lo europeo", sino, en todo caso, por recordar que está vigente. En este sentido, así como Kristal (2002) relativiza el modelo propuesto por Moretti sobre el desarrollo y diseminación de la novela, pues para el caso latinoamericano resulta indispensable considerar los géneros poético y ensayístico, deberíamos decir que, para el género policial, el enfoque de Moretti sí puede ser pertinente: el policial es creado y desarrollado en Occidente y, luego, diseminado como "ola" por otros países (de los que Argentina es un significativo ejemplo), aunque con la adopción de características particulares -el movimiento del "árbol", es decir, la ramificación, la adopción de rasgos específicos (Moretti 2007 [2005]: 67-92)-.

Aquí, además, nos interesa detenernos en un aspecto puntual de la crítica de Kristal a Moretti, pues la respuesta de aquel supone cierta teoría o premisa falsacionista que, formulada de manera extrema, nos diría algo así: si en un espacio y en un contexto histórico determinado la teoría de Moretti no se cumple, entonces no sirve. Sin embargo, este tipo de afirmaciones marcaría un camino según el cual una disciplina como la literatura mundial -o la literatura comparada- tendría que dar respuestas "verdaderas" sobre el "mundo", cuando, quizás, lo que la fortalece sería, al decir de Geertz respecto a la antropología interpretativa, el refinamiento del debate antes que el perfeccionamiento de un consenso (2003: 39). En este sentido, a continuación esbozamos una segunda ronda de reflexiones para pensar la literatura policial en su escala mundial.

\section{ALGUNAS PREMISAS DESDE UN ENFOQUE SISTÉMICO}

Pensar la literatura policial mundial desde un enfoque sistémico acarrea, en principio, la necesidad de mencionar la perspectiva teórica con la que suele confrontarse este tipo de abordaje, basada en la close reading. Algunos de los comparatistas más reconocidos, como Apter, Damrosch, Dimock y Kadir, trabajan en este linaje de la metodología filológica heredada de Auerbach y Spitzer (D'haen 2012: 100) -aunque, por supuesto, close reading y método filológico no necesariamente son sinónimos-. A veces, de parte de esta tradición, pareciera que existe cierto rechazo visceral a cualquier aproximación sistémica; Spivak, por ejemplo, consigna: “The world systems theorists upon 
whom Moretti relies are now producing sinocentric systems that are equally useless for literary study -that must depend on texture- because they equate economic with cultural systems" (2003: 108). De todos modos, este rechazo no es homogéneo entre los comparatistas de orientación filológica; basta con observar la definición de Damrosch sobre la literatura mundial para encontrar la presencia del factor sistémico:

I take world literature to encompass all literary works that circulate beyond their culture of origin, either in translation or in their original language [...]. In its most expansive sense, world literature could include any work that has ever reached beyond its home base, but Guillén's cautionary focus on actual readers makes good sense: a work only has an effective life as world literature whenever, and wherever, it is actively present within a literary system beyond that of its original culture (2003: 4).

Por lo tanto, más que adoptar o descartar tal o cual modelo, con cierto prejuicio epistemológico de que uno excluye al otro - o de que debemos hacer las cosas de una forma, tal como indica la cita de Spivak según la cual los estudios literarios deben depender de la textura-, aquí sencillamente optamos por meditar sobre algunas ideas que pueden derivarse de un abordaje sistémico, sin que esto suponga, de ninguna manera, que se trata de un modelo "superador" frente a otras opciones.

Ahora bien, está claro que los enfoques sistémicos en los estudios literarios no son ninguna novedad. Al menos podemos mencionar a dos autores que trabajan en dicha dirección y que consideran la dimensión internacional de los fenómenos literarios: Even-Zohar y Beecroft. Por un lado, los desarrollos de Even-Zohar (1979; 1990), en torno a la denominada teoría de los polisistemas incluyen un aparato conceptual sobre sistemas dinámicos, traducciones, transferencias, interferencias, divisiones entre núcleos y periferias, etcétera. Por otro, Beecroft (2008) postula un atractivo paradigma de seis modos epicórico, pancórico, cosmopolita, vernáculo, nacional y global-, con el que quizá podríamos evaluar, dentro de la literatura mundial, distintos niveles de funcionamiento de la literatura policial. Él dice inspirarse en el enfoque ecológico de Luhmann, perspectiva que, según considera, le permite deshacerse de la carga semántica de teorías económicas que arrastran los desarrollos de Casanova y Moretti. De todas formas, según observamos, Beecroft solo se remite a este aspecto ecológico, en tanto pasa por alto otros que son tan o 
más importantes ${ }^{9}$. De nuestra parte, por lo tanto, creemos que otros conceptos de Luhmann pueden ser útiles para concebir el -o, mejor dicho, un-cruce entre literatura policial y literatura mundial.

Recordemos que, según Luhmann, un sistema consiste en la distinción entre sistema y entorno (1998: 38). Los sistemas, desde esta perspectiva, tienen algunas propiedades constitutivas: clausura operativa, autorreferencialidad y autopoiesis ${ }^{10}$. Particularmente, los sistemas sociales están formados por operaciones específicas, comunicaciones, que le permiten distinguirse de su entorno. De esta forma, Luhmann entiende a la sociedad como "un sistema social autopoiético, consistente de comunicaciones y reproductor de comunicaciones por medio de comunicaciones (1998: 30).

Según advertimos, la lógica de un sistema autopoiético, de un sistema operativamente cerrado que genera sus propias comunicaciones sobre lo policial en base a la recursividad de comunicaciones anteriores sobre el género policial, puede servirnos para pensar cierta perspectiva que no desplace la atención desde "lo policial" hacia otros aspectos. Lo sustantivo de dicho sistema sería justamente las comunicaciones sobre "lo policial" -comunicaciones que incluyen a las ficciones, pero también papers, conferencias, notas en diarios, etcétera-.

Con esta formulación podemos retomar nuestra crítica a los libros que compilan aportes sobre la literatura policial a escala internacional pero

9 Resulta curioso que Beecroft emplea a Luhmann para tomar distancia de las elaboraciones de Casanova y Moretti, aunque, desde cierta óptica, algunos conceptos del sociólogo alemán, como la clausura operativa o la autopoiesis, podrían ser pensados en sintonía con los desarrollos de Casanova sobre el capital literario, su especificidad y sus reglas autónomas de (re)producción.

10 Para una primera aproximación a estos conceptos, podemos remitirnos a "El concepto de sociedad" (Luhmann 1998: 51-67), así como al resto de los ensayos breves que conforman Modernidad y complejidad: De la unidad a la diferencia, quizás antes de abordar los más extensos Sistemas sociales o La sociedad de la sociedad. Cabe aclarar que el concepto de sistema, según Luhmann, implica una clausura operativa, es decir, se trata de sistemas cerrados, a diferencia de los sistemas concebidos, por ejemplo, por Even-Zohar (1979), que los teoriza como abiertos -también es cierto que Luhmann y Even-Zohar provienen de tradiciones teóricas distintas: el primero puede ser considerado un neoparsoniano dentro del área de la teoría sociológica, en tanto que el segundo es un heredero del formalismo ruso, aunque esto no anula la comparación, pues en las formulaciones de Parsons (1966) los sistemas intercambian inputs y outputs con el medioambiente, es decir, también son concebidos como abiertos-. 
con un eje en otros aspectos, como los procesos identitarios o los Estados nacionales. Entonces, desde la construcción de una lógica sistémica de lo policial, la crítica a estos libros radica en que abordan el género policial con arreglo a categorías conceptuales que no necesariamente entran en juego con el policial: al hablar de procesos identitarios y culturales o de Estados nacionales, pareciera que lo policial a nivel global se activa y cobra valor solo en conexión con estos otros problemas o conceptos. En cambio, según consideramos, sería necesario pensar lo policial desde lo policial, es decir, autopoiéticamente y de manera cerrada. Esta formulación, que puede sonar un poco tautológica, tampoco excluye esos otros elementos (identidad, Estado, nación, etcétera), pero, en todo caso, los contempla como posibles "irritaciones" que formarían parte del entorno del sistema (cuando no como elementos de las propias comunicaciones).

Por ejemplo, en la introducción a Globalization and the State in Contemporary Crime Fiction. A World of Crime, Pepper y Schmid (2016) sostienen que hablar de Estados-naciones puede resultar obsoleto cuando analizamos un mundo globalizado, aunque, en verdad, no lo sea en absoluto. Nosotros acordamos con ellos en que hablar de literatura policial puede acarrear hablar de Estados y naciones, en el mismo sentido en que puede implicar hablar sobre crímenes, pero hablar de policiales tampoco es hablar necesariamente sobre crímenes, y menos de los crímenes del orden social real. Aquí es donde hallamos la asunción de un punto que puede ser problematizado: el crimen es tematizado y usado en las tramas de las novelas policiales, pero esto no significa que hablar de policiales tenga que derivar en hablar de crímenes ${ }^{11}$. De hecho, como lector de policiales argentinos no estoy obligado a conocer la tasa de encarcelamiento del país, ni las condiciones de las prisiones, ni las estadísticas sobre la cantidad de delitos cometidos, ni sobre las instituciones que se encargan de gestionar la criminalidad, etcétera. Puede sonar básico y tautológico, pero no debemos obviar que hablar de ficciones policiales

11 No se nos escapa que existe una tendencia, en los estudios en lengua inglesa de los últimos años, a nombrar al género como crime fiction en vez de detective fiction (Ascari 2007: 5-8). Pero, en última instancia, habría que tomar con cuidado a los que usan esta etiqueta como Knight (2004: xii)-, pues muchas veces parece que asistimos a una vaguedad conceptual que no distingue entre el problema del crimen en el orden social real y el problema de las representaciones del crimen en la literatura policial (problemas que, por supuesto, no pueden no estar vinculados, lo que no es lo mismo que dejar un vacío conceptual de indiferencia entre ambos). 
implica hablar de ficciones policiales ${ }^{12}$, y en este particular sentido apelamos a la lógica luhmanniana: lo policial produce lo policial, comunicaciones de y sobre lo policial se forman de comunicaciones de y sobre lo policial ${ }^{13}$. De esta forma, quizás, podamos pensar una pauta para concebir el género a nivel mundial y no atar dicha escala a categorías que, en última instancia, le son externas, como la nación ${ }^{14}$.

Por cierto, en su diseño de una teoría sobre la sociedad, Luhmann empieza por descartar ciertos principios rectores para otras teorías, como el sujeto o la nación, y que él clasifica como prejuicios "humanista" y "nacionalista" -además de que consigna un tercero, de orden epistemológico, que aquí dejamos de lado-:

1) El primero se refiere a la hipótesis de que la sociedad consiste en seres humanos o de relaciones entre ellos. Yo llamo a esto el prejuicio humanista. ¿Cómo puede entenderse esto? ¿Es que la sociedad consiste acaso en brazos y piernas, ideas y enzimas? ¿Le corta el peluquero el pelo a la sociedad? ¿Necesita a veces la sociedad insulina? ¿Qué tipo de operación caracteriza a la sociedad, si a ella pertenece tanto la química celular como la alquimia de la represión de lo inconsciente? Aparentemente, el prejuicio humanista se apoya de forma deliberada sobre la imprecisión conceptual, por lo que uno ha de preguntarse: ¿por qué? Entonces, el teórico se convierte a sí mismo en paciente.

2) El segundo prejuicio que bloquea el desarrollo conceptual radica en el presupuesto de una pluralidad territorial de sociedades. China es una, Brasil otra, Paraguay es una, y entonces Uruguay también es

12 "If you read adetective story, you read a detective story" (1988: 155), consigna Moretti cuando intenta concebir a la literatura policial como un factor propio de la autonomía de la esfera de la cultura -y no como una suerte de "reflejo superestructural" de la base económica del modo de producción capitalista-.

13 Cuando decimos que lo policial deriva de lo policial, no nos referimos a la técnica compositiva basada en la autorreferencia literaria -por ejemplo, Gaboriau citando a Poe en El misterio del cuarto amarillo-, sino a una lógica sistémica más amplia -que, por cierto, incluye a este tipo de comunicaciones voluntariamente autorreferenciales desde el punto de vista de la técnica compositiva-.

14 No perdemos de vista que, en este trabajo, partimos de visibilizar tanto al sujeto que enuncia como a la nación desde la que lo hace. Pero, justamente, estamos tratando de plantear otra forma de ver las cosas, en las que tanto el sujeto como la nación no están en el centro de la explicación. 
otra. Todos los esfuerzos para realizar una delimitación cuidadosa han resultado baldíos, independientemente de que hayan reparado en la organización estatal, la lengua, la cultura o la tradición. Es cierto que hay diferencias insalvables entre las condiciones de vida en estos territorios, pero ellas tienen que ser explicadas como tales diferencias dentro la sociedad, no pudiendo presuponerse como diferencias entre sociedades. ¿O es que queremos resolver los problemas centrales de la sociología por medio de la geografía? (1998: 52-53).

Quizás algo de esto podríamos aplicar a una concepción de la literatura policial a escala mundial: no importan las naciones o las personas. Esto, como venimos insistiendo, no borra las naciones y las personas, pero ellas no están necesariamente en el centro de una concepción sistémica sobre el género policial -sistema en el que, en todo caso, pueden participar desde el entorno- ${ }^{15}$.

Esta definición luhmanniana también nos ahorraría el problema del vocablo "sistema", al que, suponemos, el propio Moretti se refiere, según una de sus acepciones comunes, como un conjunto relacionado y jerarquizado de partes ${ }^{16}$. Pero la no definición de una palabra tan sensible también puede debilitar toda la argumentación que sigue después ${ }^{17}$. De cualquier modo, lo

15 Más allá de hacerlo con vaivenes, Pepper y Schmid sostienen que el Estado es una de las condiciones del género policial (2016: 8), lo cual es cierto, pero, en todo caso, no es menos cierto que decir que básicamente cualquier fenómeno del orden social del siglo XXI tiene un estrecho vínculo con el Estado-nación.

16 Moretti (2003), en efecto, se apoya explícitamente en Even-Zohar, quien concibe a los sistemas como "both the idea of a closed net-of-relations, in which the members receive their values through their respective oppositions, and the idea of an open structure consisting of several such concurrent nets-of-relations" (1979: 291).

17 No decimos con esto que las conjeturas de Moretti se caigan, pero sí es cierto que caracterizar como uno y desigual algo que no terminamos de saber qué o cómo es, nos lleva a la obligación de señalar una apuesta teórica que, a la hora de hablar de "sistema", nos entrega un cheque en blanco. En este sentido, quizás la precisión léxica por la que opta Casanova, al hablar de "espacio literario mundial" (2001 [1999]), pareciera ser más cuidadosa. De cualquier modo, insistimos, y más allá de la "terapia semántica" (Abend 2008) a la que nos vemos impelidos en disciplinas sociales y humanísticas, tampoco debemos dejar de hacer notar que ciertos vacíos en algunas formulaciones no anulan necesariamente la totalidad de los argumentos, tal como consideramos que ocurre con las ideas de Moretti. Aunque, insistimos, una mayor precisión en algunas definiciones puede eliminar aspectos poco claros: por ejemplo, Arac (2002) critica a Moretti en que su distinción entre centro y periferia es sincrónica, pero en un modelo luhmanniano una crítica de este estilo no tendría demasiado sostén, pues, en nuestro 
central del planteo de Moretti reside en un intento por hacer inteligible una totalidad. Tal como sostiene Arac, tanto Moretti como Auerbach -este último en su texto "Philology and Weltliteratur" (1969)- se posicionan ante una ampliación de lo cognoscible y la necesidad de hacer algo ante eso, de crear formas de conocimiento que comiencen por reconocer la imposibilidad de saber todo, de leer suficiente:

My purpose in adducing Auerbach is first to suggest that the problems he and Moretti see are much the same: the expansion of the knowable produced by the emergence of a truly world-spanning literature, and the need to develop new procedures of knowledge that recognize the impossibility of knowing everything, of reading enough -and which therefore must define imaginatively framed points of entry into the materials in order to make possible historical investigation (Arac 2002: 41-42).

En este último sentido de encontrar - $\mathrm{O}$, al menos, buscar-puntos de entrada creativos para reflexionar en torno a lo inabarcable del género policial, la teoría de Luhmann sobre los sistemas sociales autoorganizados y autopoiéticos quizá pueda brindarnos justamente eso: un punto de entrada para pensar la ingente ficción policial, a nivel mundial, desde ella misma. Podría tratarse de una buena herramienta para, al decir de Freund, organizar la desesperación $(1986: 24)^{18}$.

caso de estudio, son justamente los encadenamientos de comunicaciones sobre lo policial el sustrato que constituye el sistema en su duración histórica.

18 Desde luego, así como una visión sistémica, según consideramos, permite establecer un argumento más cerrado en torno a la unidad y la coherencia de "lo policial" a nivel mundial, esta perspectiva igualmente deja de lado el factor del poder, que los enfoques de Casanova y Moretti sí contemplan con mayor rigurosidad. Asimismo, como venimos diciendo, la asunción de la unidad del género a nivel mundial también puede resultar problemática y, en este sentido, nos remitimos al reciente aporte de Siskind y su crítica sobre el propio empleo del vocablo "mundo":

El punto es que el mundo no es, ni debe ser considerado, un datum; el mundo no es (no puede ser) lo dado; no es (ni puede ser) un supuesto que preexista a las intervenciones críticas o estéticas que tienen la obligación de postular en términos contingentes y concretos, mundo o no-mundo, la estructura que sostiene y soporta su intervención discursiva. Todo texto que trasciende la inmediatez de lo local postula un mundo, una formación transcultural distinta y singular que podemos (o no) llamar "mundo", dependiendo de si queremos o no crear la ilusión falaz en nuestra audiencia de que el "mundo" (entre comillas para referir 


\section{BIBLIOGRAFÍA}

Abend, Gabriel. "The meaning of "theory”". Sociological Theory 26/2 (2008): 173-199.

Alexander, Jeffrey. "La centralidad de los clásicos". Giddens, Anthony (ed.). La teoría social hoy. México D. F.: Alianza Editorial, 1990. 22-80.

Anderson, Jean, Carolina Miranda y Barbara Pezzotti (eds.). The Foreign in International Crime Fiction: Transcultural Representations. Nueva York: Continuum, 2012.

Apel, Karl-Otto."El problema de la fundamentación última filosófica a la luz de una pragmática trascendental del lenguaje". Diánoia 21 (1975): 140-173.

Arac, Jonathan. “Anglo-Globalism?”. New Left Review 16 (2002): 35-45.

Ascari, Maurizio. A Counter-history of Crime Fiction: Supernatural, Gothic, Sensational. Basingstoke: Palgrave-MacMillan, 2007.

Auerbach, Erich. "Philology and Weltliteratur". The Centennial Review 13/1 (1969):1-17.

Ayala Gauna, Velmiro. "Intención”. Los casos de Don Frutos Gómez. Buenos Aires: Huemul, 1979 [1955]. 43-6.

Baetens, Jan. "World Literature and Popular Literature: Toward a Wordless Literature?" D'haen, Theo, David Damrosch y Djelal Kadir (eds.). The Routledge Companion to World Literature. Abingdon, Nueva York: Routledge, 2012. 336-344.

Bajtin, Mijaíl. "El problema de los géneros discursivos". Estética de la creación verbal. Buenos Aires: Siglo XXI, 2011 [1982]. 245-290.

Bazin, André. "The Western, or the American Film par excellence". What is Cinema? (Vol. II). Berkeley, Los Ángeles, Londres: University of California Press, 2005 [1971]. 140-148.

Beecroft, Alexander. "World Literature Without a Hyphen: Towards a Typology of Literary Systems". New Left Review 54 (2008): 87-100.

"On the Tropes of Literary Ecology. The Plot of Globalization". Habjan, Jernej y Fabienne Imlinger (eds.). Globalizing literary genres: literature, history, modernity. Abingdon, Nueva York: Routledge, 2016. 195-212.

Behdad, Ali y Dominic Thomas (eds.). A Companion to Comparative Literature. Chichester: Wiley-Blackwell, 2011.

a la estructura contingente sobre la que inscribimos nuestro discurso crítico) coincide con el mundo, con la totalidad imaginaria que proyectamos sobre el planeta (2017: 14-15).

Más allá de la agudeza de la reflexión, quizás haya cierta objeción que se le pueda plantear en términos de que su enunciación de que "el mundo no existe", como discusión del concepto de "lo mundial" en la literatura mundial, puede leerse como una suerte de autocontradicción performativa -en el sentido señalado por Apel (1975)-, es decir, se enuncia algo que se niega, pero, entonces, el propio acto de enunciar niega la negación -o sea: afirmando que el mundo no existe, enunciamos el mundo y lo afirmamos-. 
Bermann, Sandra. "World Literature and Comparative Literature". D'haen, Theo, David Damrosch y Djelal Kadir (eds.). The Routledge Companion to World Literature. Abingdon, Nueva York: Routledge, 2012. 169-179.

Casanova, Pascale. La República mundial de las Letras. Barcelona: Anagrama, 2001 [1999].

Cohen, Margaret. "Narratology in the Archive of Literature". Representations 108/1 (2009): 51-75.

Cook, Michael. Narratives of Enclosure in Detective Fiction: The Locked Room Mystery. Basingstoke: Palgrave-MacMillan, 2011.

Damrosch, David. What is World Literature? Princeton: Princeton University Press, 2003.

D'haen, Theo. The Routledge Concise History of World Literature. Abingdon, Nueva York: Routledge, 2012.

D'haen, Theo, David Damrosch y Djelal Kadir (eds.). The Routledge Companion to World Literature. Abingdon, Nueva York: Routledge, 2012.

De Rosso, Ezequiel. Nuevos secretos. Transformaciones del relato policial en América Latina. 1990-2000. Buenos Aires: Liber, 2012.

De Santis, Pablo. El enigma de París. Buenos Aires: Planeta, 2008 [2007].

Del Monte, Alberto. Breve historia de la novela policiaca. Madrid: Taurus, 1962.

Di Paolo, Osvaldo. Cadáveres en el armario. El policial palimpséstico en la literatura argentina contemporánea. Buenos Aires: Teseo, Austin Peay State University, 2011.

Díaz, César. La novela policíaca. Síntesis histórica a través de sus autores, sus personajes y sus obras. Barcelona: Acervo, 1973.

Domínguez, César, Haun Saussy y Darío Villanueva. Lo que Borges enseñó a Cervantes. Introducción a la literatura comparada. Barcelona: Taurus (Penguin Random House), 2016.

Erdmann, Eva. "Nationality International: Detective Fiction in the Late Twentieth Century". Krajenbrink, Marieke y Kate M. Quinn (eds.). Investigating Identities: Questions of Identity in Contemporary International Crime Fiction. Amsterdam: Rodopi, 2009. 11-26.

Even-Zohar, Itamar. "Polysystem Theory". Poetics Today 1(1979): 287-310.

"Polysystem Studies". Poetics Today 11/1 (1990). Disponible en: http://www.tau. ac.i1/ itamarez/works/books/Even-Zohar_1990--Polysystem\%20studies.pdf

Ferris, David. "Why Compare?". Behdad, Ali, y Dominic Thomas (eds.). A Companion to Comparative Literature. Chichester: Wiley-Blackwell, 2011. 28-45.

Freund, Julien. Sociología de Max Weber. Barcelona: Península, 1986.

Garrido Miñambres, Germán. "Géneros literarios y literatura comparada". Revista de Literatura 143 (2010): 11-32.

Geertz, Clifford. "Descripción densa: hacia una teoría interpretativa de la cultura". La interpretación de las culturas. Barcelona: Gedisa, 2003. 19-40.

Gupta, Suman. "On Mapping Genre. Literary Fiction/Genre Fiction and Globalization Processes". Habjan, Jernej y Fabienne Imlinger (eds.). Globalizing Literary Genres: Literature, History, Modernity. Nueva York, Abingdon: Routledge, 2016. 213-227.

Hall, Stuart. "Introducción: ¿quién necesita «identidad»?”. Hall, Stuart, y Paul Du Gay (comps.). Cuestiones de identidad cultural. Buenos Aires: Amorrortu, 2003. 13-39. 
Habjan, Jernej. "Introduction: Globalizing Literary Genres". Habjan, Jernej y Fabienne Imlinger (eds.). Globalizing Literary Genres: Literature, History, Modernity. Abingdon, Nueva York: Routledge, 2016. 1-14.

Heath, Stephen. "The Politics of Genre". Prendergast, Christopher (ed.). Debating World Literature. Londres, Nueva York: Verso, 2004. 163-174.

Hoveyda, Fereydoun. Historia de la novela policiaca. Madrid: Alianza, 1967.

Huggan, Graham. "The Trouble with World Literature”. Behdad, Ali y Dominic Thomas (eds.). A Companion to Comparative Literature. Chichester: Wiley-Blackwell, 2011. 490-506.

King, Stewart. "Crime Fiction as World Literature". Clues: A Journal of Detection 32/2 (2014): 8-19.

Knight, Stephen. Form and Ideology in Crime Fiction. Londres: MacMillan, 1980.

Crime Fiction, 1800-2000: Detection, Death, Diversity. Basingstoke: PalgraveMacmillan, 2004.

The Mysteries of the Cities: Urban Crime Fiction in the Nineteenth Century. Jefferson, Carolina del Norte, Londres: McFarland, 2012.

Krajenbrink, Marieke y Kate M. Quinn (eds.). Investigating Identities: Questions of Identity in Contemporary International Crime Fiction. Amsterdam: Rodopi, 2009.

Kristal, Efrain. "Considering Coldly... A Response to Franco Moretti". New Left Review 15 (2002): 61-74.

Lafforgue, Jorge y Jorge B. Rivera. Asesinos de papel. Ensayos sobre narrativa policial. Buenos Aires: Colihue, 1996 [1977].

Luhmann, Niklas. "El concepto de sociedad". Modernidad y complejidad: De la unidad a la diferencia. Madrid: Trotta, 1998.

Mattalia, Sonia. La ley y el crimen. Usos del relato policial en la narrativa argentina (18802000). Madrid, Fráncfort del Meno: Iberoamericana,Vervuert, 2008.

Mignolo, Walter. "El pensamiento decolonial: desprendimiento y apertura. Un manifiesto". Castro-Gómez, Santiago y Ramón Grosfoguel (eds.). El giro decolonial: reflexiones para una diversidad epistémica más allá del capitalismo global. Bogotá: Siglo del Hombre Editores, Universidad Central, Pontificia Universidad Javeriana, 2007. 25-46.

Miller, Vivien y Helen Oakley (eds.). Cross-Cultural Connections in Crime Fictions. Basingstoke, Nueva York: Palgrave Macmillan, 2012.

Mira, Juan José. Biografía de la novela policiaca. Barcelona: AHR, 1956.

Moretti, Franco. "Clues". Signs Taken For Wonders: Essays in the Sociology of Literary Forms. Londres, Nueva York: Verso, 1988. 130-156.

“Conjectures on World Literature”. New Left Review 1 (2000a): 54-68.

"The Slaughterhouse of Literature". Modern Language Quarterly 61/1 (2000b): 207-227.

"More Conjectures". New Left Review 20 (2003): 73-81.

Graphs, Maps, Trees: Abstract Models for Literary Study. Londres, Nueva York:

Verso, 2007 [2005]. 
Nilsson, Louise, David Damrosch y Theo D'haen. "Introduction: Crime Fiction as World Literature". Nilsson, Louise, David Damrosch y Theo D'haen (eds.). Crime Fiction as World Literature. Nueva York: Bloomsbury, 2017. 1-9.

Parsons, Talcott. "The Concept of Society: the Components and Their Interrelations". Societies: Evolutionary and Comparative Perspectives. Nueva Jersey: Prentice-Hall, 1966. 5-29.

Pepper, Andrew y David Schmid. "Introduction: Globalization and the Statein Contemporary Crime Fiction". Pepper, Andrew y David Schmid (eds.). Globalization and the State in Contemporary Crime Fiction. A World of Crime. Londres: Palgrave Macmillan, 2016. 1-19.

Piglia, Ricardo. "Introducción”. Ricardo Piglia (comp.), Cuentos de la serie negra. Buenos Aires: Centro Editor de América Latina, 1979. 7-14.

"Lectores imaginarios". El último lector. Buenos Aires: Anagrama, 2005. 77-102.

"Sobre el género policial". Crítica y ficción. Buenos Aires: Anagrama, 2006 [1986]. 59-62.

Ponce, Néstor. Diagonales del género. Estudios sobre el policial argentino. San Luis Potosí: El Colegio de San Luis, 2013 [2001].

Prendergast, Christopher. "The World Republic of Letters". Christopher Prendergast (ed.). Debating World Literature. Londres, Nueva York: Verso, 2004. 1-25.

Priestman, Martin. Detective Fiction and Literature: The Figure on the Carpet. Basingstoke, Londres: MacMillan, 1990.

Setton, Román. Los orígenes de la narrativa policial en la Argentina: recepción y transformación de modelos genéricos alemanes, franceses e ingleses. Madrid, Fráncfort del Meno: Iberoamericana,Vervuert, 2012.

Schmid, David. "From the Locked Room to the Globe: Space in Crime Fiction". Miller, Vivien y Helen Oakley (eds.). Cross-Cultural Connections in Crime Fictions. Basingstoke, Nueva York: Palgrave Macmillan, 2012. 7-23.

Siskind, Mariano. "The Genres of World Literature: the Case of Magical Realism". Theo D'haen, David Damrosch y Djelal Kadir (eds.). The Routledge Companion to World Literature. Abingdon, Nueva York: Routledge, 2012. 345-355.

"Modernismo global y literatura mundial: Reflexiones sobre las dislocaciones cosmopolitas del significado francés". Revista Chilena de Literatura 96 (2017): 13-28.

Škvorecký, Josef. Nápady čtenáře detektivek. Praga: Československý spisovatel, 1967.

Spivak, Gayatri. Death of a Discipline. Nueva York: Columbia University Press, 2003.

Tötösy de Zepetnek, Steven y Tutun Mukherjee (eds.). Companion to Comparative Literature,

World Literatures, and Comparative Cultural Studies. Nueva Delhi: Cambridge University Press India, Foundation Books, 2013.

Valle, Manuel. El signo de los cuatro (Vols. I-IV). Granada: Comares, 2006.

Waleis, Raúl (Luis V. Varela). La huella del crimen. Buenos Aires: Adriana Hidalgo, 2009. 